\title{
PONENCIA: ESTRATEGIAS PARA LOGRAR UNA CURA FUNCIONAL DEL VIH
}

Ponencia presentada en la Facultad de Medicina Humana Daniel Alcides Carrión. Universidad Nacional San Luis Gonzaga de Ica, Perú; Nov 2018.

\section{De La Torre Erick ${ }^{1, a}$}

1. Investigador del Instituto de Salud Carlos III, España

a. Biólogo - Máster en Virología

Hace 35 años que conocemos a este virus y aún no hemos conseguido doblegarlo por completo. Sin embargo hay mucha investigación en este campo cuyo objetivo es contribuir a encontrar una cura funcional para la infección, que consiste en limitar el tamaño del reservorio viral y controlar la carga viral a través de una respuesta inmunológica adecuada (1). Entre un $2-5 \%$ de los pacientes que están infectados por el VIH, son denominados LTNPs (long term non-progressors o progresores lentos), los cuales son capaces de mantener niveles altos de células T CD4 y/o baja carga viral sin estar en tratamiento antirretroviral, los cuales constituyen un modelo natural de cura funcional y que hay diversos factores genéticos o inmunológicos que están involucrados en este control de la infección $(2,3)$.

La dinámica y los mecanismos involucrados en la latencia viral y en la persistencia de reservorios virales son muy complejos, y constituyen el mayor obstáculo para lograr una cura funcional de la infección (4). Las diversas estrategias para que se han evaluado, y que algunas siguen en curso, durante estos últimos años para disminuir o limitar la expansión de los reservorios, así como mejorar los parámetro inmunológicos, dentro del contexto de conseguir una cura funcional, son:

Potenciación inmunológica. Se han diseñado vacunas terapéuticas que expresan la región Gag del VIH-1, con el fin potenciar la respuesta de las células citotóxicas (linfocitos T CD8) que se ven afectadas durante la infección. También se ha evaluado la acción de compuestos anti-PD1/PDL1 y anti-CTL4, así como la estimulación de TLR7 (3).

Activación del reservorio. La estrategia shock and kill apunta a activar la expresión viral de las células latentemente infectadas, mediante compuestos que tengan la capacidad de activar la transcripción viral (HDACi, agonistas de PKC, entre otros), lo cual permitiría le permitiría a las células T citotóxicas reducir el reservorio. Es estrategia estaría indicada para la fase crónica de la infección, con el fin de disminuir la cantidad los reservorios virales. Nuevos enfoques proponen combinar la potenciación inmunológica con la activación del reservorio para lograr una respuesta más eficaz $(2,3,4)$.

Terapia génica: se han diseñado diversas enzimas moleculares, como TALEN, CRISPR/Cas9 y ZFN, con una especificidad dirigida alterar al gen CCR5 (que conlleva a la generación de células resistentes a la infección) o a regiones del provirus para generar virus defectuosos o inactivar sus transcripción (3).

Fármacos pro-latencia: se han evaluado fármacos que son utilizados para otras enfermedades, como el dasatinib. Esta estrategia estaría indicada durante la primoinfección, para limitar la expansión de reservorios virales. También se están evaluando otros fármacos que conducen a las células que son diana de la infección a mantener un estado latente, modificando su estado metabólico (6).

Transplante de células madre: el paciente de Berlín es el único caso conocido de curación y remisión del virus, después de un trasplante de células madre que poseían una deleción genética CCR5 delta32 (que afecta al co-receptor CCR5, el cual es utilizado por el virus para la entrada a la célula) y posteriores tratamientos de quimioterapia. Ha habido otras aproximaciones siguiendo esta estrategia, que incluyen a los pacientes de Boston, en donde el virus remitió después de discontinuar la terapia antirretroviral, y actualmente se ha publicado un gran avance en un grupo de pacientes de España $(2,3,7)$.

En conclusión, se debe seguir invirtiendo en investigación para encontrar una vacuna o cura para la infección por el $\mathrm{VIH}$, así como en estrategias y políticas públicas que permitan evitar nuevas infecciones del virus que ha causado la muerte de 35 millones de personas desde el comienzo de la epidemia hace 35 años. 


\section{REFERENCIA BIBLIOGRÁFICAS}

1. Martin GE, Frater J. 2018. Post-treatment and spontaneous HIV control. Curr Opin HIV AIDS. 13(5):402-407

https://www.ncbi.nlm.nih.gov/pubmed/2987891 4

2. Liu C, Ma X, Liu B, Chen C, Zhang H. 2015. HIV-1 functional cure: will the dream come true? BMC Med. 13: 284

https://www.ncbi.nlm.nih.gov/pubmed/?term $=\mathrm{H}$ IV-1+functional+cure $\% 3 \mathrm{~A}+$ will +the+dream +co me+true\%3F

3. Caroline P Passaes, Asier Sáez-Cirión. 2014. HIV cure research: advances and prospects. Virology, Elsevier, 454-455, pp.340-5

https://www.ncbi.nlm.nih.gov/pubmed/2463625 2

4. Coiras $M$, López-Huertas MR, Pérez-Olmeda $M$, Alcamí J. Understanding HIV-1 latency provides clues for the eradication of long-term reservoirs. 2009. Nat Rev Microbiol. 7(11):798-812. https://www.ncbi.nlm.nih.gov/pubmed/1983448 0

5. UNAIDS DATA 2018- Joint United Nations Programme on HIV/AIDS

http://www.unaids.org/sites/default/files/media_ asset/unaids-data-2018_en.pdf
6. Bermejo M, López-Huertas MR, García-Pérez J, Climent N, Descours B, Ambrosioni J, Mateos $E_{,}$ Rodríguez-Mora S, Rus-Bercial L, Benkirane $\mathrm{M}_{\text {, }}$ Miró JM, Plana M, Alcamí J, Coiras M. 2016. Dasatinib inhibits HIV-1 replication through the interference of SAMHD1 phosphorylation in CD4+ T cells. Biochem Pharmacol; 106:30-45. https://www.ncbi.nlm.nih.gov/pubmed/2685149 1

7. Salgado M; Kwon M; Gálvez C; Badiola J, Nijhuis M; Bandera A; Balsalobre P, Miralles P, Buno I, Martinez-Laperche $C$, Vilaplana $C$, Jurado $M_{t}$ Clotet $\mathrm{B}$; Wensing $\mathrm{A}$; Martinez-Picado J and Diez-Martin JL. 2018. Mechanisms That Contribute to a Profound Reduction of the HIV-1 Reservoir After Allogeneic Stem Cell Transplant. Ann Intern Med ;169(10):674-683. https://www.ncbi.nlm.nih.gov/pubmed/?term =M echanisms + That + Contribute + to + a +Profound + Reduction+of+the+HIV-1+Reservoir+After+Allo geneic+Stem+Cell+Transplant.
CITAR COMO

De La Torre Erick. PONENCIA: Estrategias para lograr una Cura funcional del VIH. En Ponencia presentada en la Facultad de Medicina Humana Daniel Alcides Carrión. Universidad Nacional San Luis Gonzaga de Ica, Perú; 2018.. Rev méd panacea.2018; 7(3): 116-117 